\title{
Three-dimensional Modeling of an Old Masonry Bridge and Assessing Its Current Capacity
}

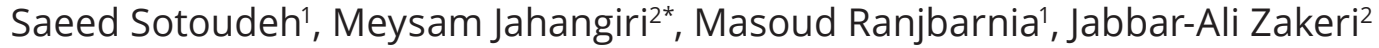 \\ ${ }^{1}$ Faculty of Civil Engineering, University of Tabriz, 29 Bahman Blvd.,Tabriz, 5166616471, Iran \\ 2 The Center of Excellence in Railway Transport, School of Railway Engineering, Iran university of Science and Technology, \\ Narmak Hengam Street, 16846-13114, Tehran, Iran \\ *Corresponding author, e-mail: m_jahangiri@rail.iusc.ac.ir
}

Received: 06 September 2019, Accepted: 22 February 2020, Published online: 30 March 2020

\begin{abstract}
Masonry bridges are among the main structures built along the road and railway routes. These structures are generally old and have historical value. Considering the increased axial load and passing speed from these bridges, an in-depth study of these structures and their potential is of paramount importance. In the present study, an old masonry arch bridge located in $475 \mathrm{~km}$ of Western Iranian railway is investigated. For the detailed modeling of this structure, a three-dimensional finite element method (3DFEM) was implemented to take into account the details of the bridge and the train passing over it. The developed model was calibrated and validated using the dynamic field test results. The obtained results showed that the increase in the axial load and train speed over the bridge must be done carefully because exceeding the travel speed of $90 \mathrm{~km} / \mathrm{h}$ and increasing the axial load from 20 to 30 ton makes serious problems in the bridge and interrupts its performance. Furthermore, it was found that the adequacy factor of the bridge under the standard load of LM71 is over 2.
\end{abstract}

Keywords

masonry bridges, finite element method, dynamic field test, model calibration, adequacy factor

\section{Introduction}

The railway transportation system is subjected to an ever-increasing demand for axial load and operation speed. To meet such demands, the railway infrastructures also must meet the new conditions. In this regard, the constructed bridges play a key role such that any defect in the performance of the bridges interrupts the performance of the whole route. One of the common types of bridges constructed over the railways is masonry bridges. These structures are generally old and their serviceability period is about to end. Besides, their maintenance is a critical issue considering their historical values. Hence, for a safe and nonstop travel, re-evaluation of these structures under new conditions seems necessary. UIC778-3 code [1] proposes several methods for evaluating the masonry bridges, for different geometries and applications. One of these methods is the one proposed by Pippard [1], i.e., MEXE, which allows estimation of the allowable operating load. Also, methods such as limit analysis equilibrium and limit analysis mechanism, two-dimensional and threedimensional finite element, discrete element analysis, and elastic and elasto-plastic analyses can be applied depending on the purpose of the analysis and geometrical conditions of the model.

In the second half of the 19th century, elasticity theory received the attention of many scientists. Fanning and Boothby [2], in a study on three masonry bridges, obtained a good agreement between the FEM results and field test results. According to their work, nonlinear FEM is a suitable method for the analysis of masonry bridges. In another study, Frýba and Pirner [3] extracted impact dynamic coefficients and natural frequencies of a railway bridge through the field tests. Moreover, using the stress monitoring of the bridge, they estimated fatigue and deterioration of the bridge and its maintenance intervals. Brencich and Sabia [4] investigated the 18-span Tanaro Bridge through several tests on the bridge body and materials and utilized the obtained results in FE modeling of the masonry bridges. The results of this study revealed that the modal analysis of the bridge needs monitoring several parts of it. Moreover, FE modeling provided valuable results on the behavior of 
the masonry bridges under operating loading and dynamic parameters. $\mathrm{Ng}$ and Fairfield [5] modified the parameters governing the behavior of a masonry bridge and performed a risk analysis on it based on a combination of Monte Carlo simulation and mechanism method. The method proposed in this research allows a realistic analysis of the bridge and improves the engineering judgment for enhancing the axial load of the masonry bridges with poor conditions. Marefat et al. [6], by conducting some force experiments and analysis of a bridge, found that the structure works as a multilayer system and show high strength, despite the cracks in its body and its carbon content. According to these authors, the accurate analysis of these cracks and incorporating the soil effects are two essential factors in convergence and simulation accuracy. Caglayan et al. [7] performed some field tests in order to characterize a large old masonry bridge in a seismically active area and calibrated the model using the FEM results. Their results demonstrate the stability of the bridge against the increased axial load. Carr et al. [8] investigated the Cernadela masonry bridge using the elastic analysis. Then, incorporating the stiffness and geometry of the bridge, they calculated the capacity of this bridge ( $\sim 14.5$ ton) through forming the first hinge. Bayraktar et al. [9], claiming that the numerical study of masonry bridges cannot be accurate enough by itself, installed some resonance-sensitive accelerometer and conducted some field tests. They selected eight masonry bridges made of stone and mortar with different ages and locations and calculated their dynamic properties using the modal analysis. They determined the frequency, damping ratio, and shape coefficients of the selected bridges through frequency zone analysis and semi-spatial statistics and compared them for all eight bridges. The output of this study is a new formula for the first frequency, a value for damping ration, and different shape coefficients for old masonry arch bridges. Ataei et al. [10] conducted some field dynamic tests on a stone bridge, calibrated their FE model, and analyzed the bridge under different conditions through dynamic analyses. The results revealed the complete safety of the bridge under operating load and inefficiency of the bridge under the standard LM71 loading. Reccia et al. [11] conducted a three-dimensional nonlinear FEM analysis on a masonry bridge using cubic solid elements and integrating two coding and software methods. They carried out nonlinear static and limit analyses on a three-dimensional complicated structure, loaded the bridge up to the standard LM71 load, and analyzed its collapse mechanism due to the effects of foundation settlement. Ataei et al. [12] performed a feasibility study on masonry arch bridges and carried out a three-dimensional FE modeling under moving loads. However, using a moving train instead of moving loads would give a more accurate estimation of the bridge's behaviors. After validation of the FE model using the field test results, four-hinge plastic mechanism and serviceability limit state applied. They concluded that the bridge can resist an increase in the axial load from 20 to 25 ton under a travel speed of 5-60 km. Elsewhere, Ataei et al. [13] performed a feasibility study on the axial load increment on an S-shape masonry bridge with a span length of $36 \mathrm{~m}$. They performed material strength tests on the cores extracted from the bridge and carried out dynamic field tests in order to calibrate the responses of a masonry bridge. Their results showed the resistance of the load against the increased axial load. They finally determined the ultimate strength coefficient of the bridge. Jahangiri and Zakeri [14, 15] investigated the effects of train speed on a train-bridge system for a concrete box bridge using FE modeling of the bridge and train for one-way and two-way routes under the velocity range of $120-350 \mathrm{~km} / \mathrm{h}$. The proximity of the natural frequencies of the bridge and loading frequencies of the train significantly affected their results in some velocities.

Based on the mentioned points, there are two common points in the majority of these studies:

- Modeling based on a moving load; however, modeling with a moving train can provide a more accurate behavior of the bridge.

- Comparing the field results and outputs of the numerical modeling; according to these studies, comparing the results of software modeling with field test is necessary for validating the modeling results.

Safety analysis of masonry bridges is done using several methods. One of the common methods in this regard is extracting their ultimate capacity $[16,17]$. This process is done by incorporating details such as materials degradation and allows plastic analysis until the failure point. However, the behavior of the structure cannot be predicted during the analysis. One approach to reach this goal is to apply FE modeling, which not only allows relatively accurate analysis of the complicated structures but also provides valuable information on the structure's behavior during the analysis. Considering the needs of the railway transportation system, the feasibility study of axial load and speed travel increase seems an essential issue. Thus, the present study was conducted on the single-line 475 masonry bridge built upon the Western Iranian Railway (Azerbaijan). 
Considering the complexity involved in the behaviors of the masonry structures, to confirm the accuracy of the FEM results, the model was validated using the field test results. The objectives followed in the present study are as follows:

- Investigating the interaction of masonry bridge-train system,

- Investigating the current situation of the bridge based on the common passing loads,

- Feasibility study of axial load increase,

- Feasibility study of passing speed increase,

- Determining the ultimate bearing capacity of the studied bridge.

\section{Research methodology}

To achieve the objectives of this research, a 3D FE model was developed for both the bridge and train. In the following, the results and sensitivity analyses performed under different conditions are presented. The assumptions of this work are as follows:

- Modeling of the bridge and train was done through FEM technique.

- Each of four-axis vehicles and six-axis vehicles was modeled with 27 and 33 degrees of freedom.

- The bridge was modeled as a single-line masonry bridge.
- The train passes over the bridge under different speeds.

- The train passes over the bridge under different axle loads.

Based on these assumptions, the steps shown in Fig. 1 were carried out.

\section{Bridge characteristics}

475 Bridge is a structure with the serviceability age of 70 years and a length of $174 \mathrm{~m}$. The bridge has four $25-\mathrm{m}$ and six 8-m spans and operates with an axial load of 20 ton and a travel speed of $60 \mathrm{~km} \mathrm{[10].}$

Figs. 2 and 3 presents a view of 475 Bridge and its spans. Also, Table 1 lists the geometrical specifications of the bridge, obtained through detailed field surveys.

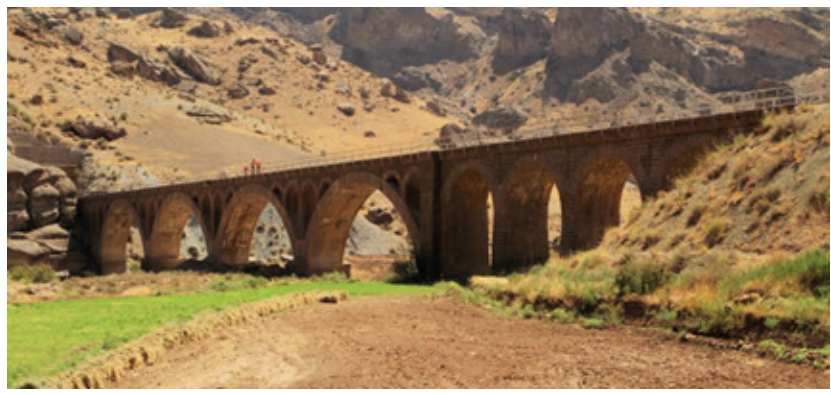

Fig. 2 A view of 475 Bridge

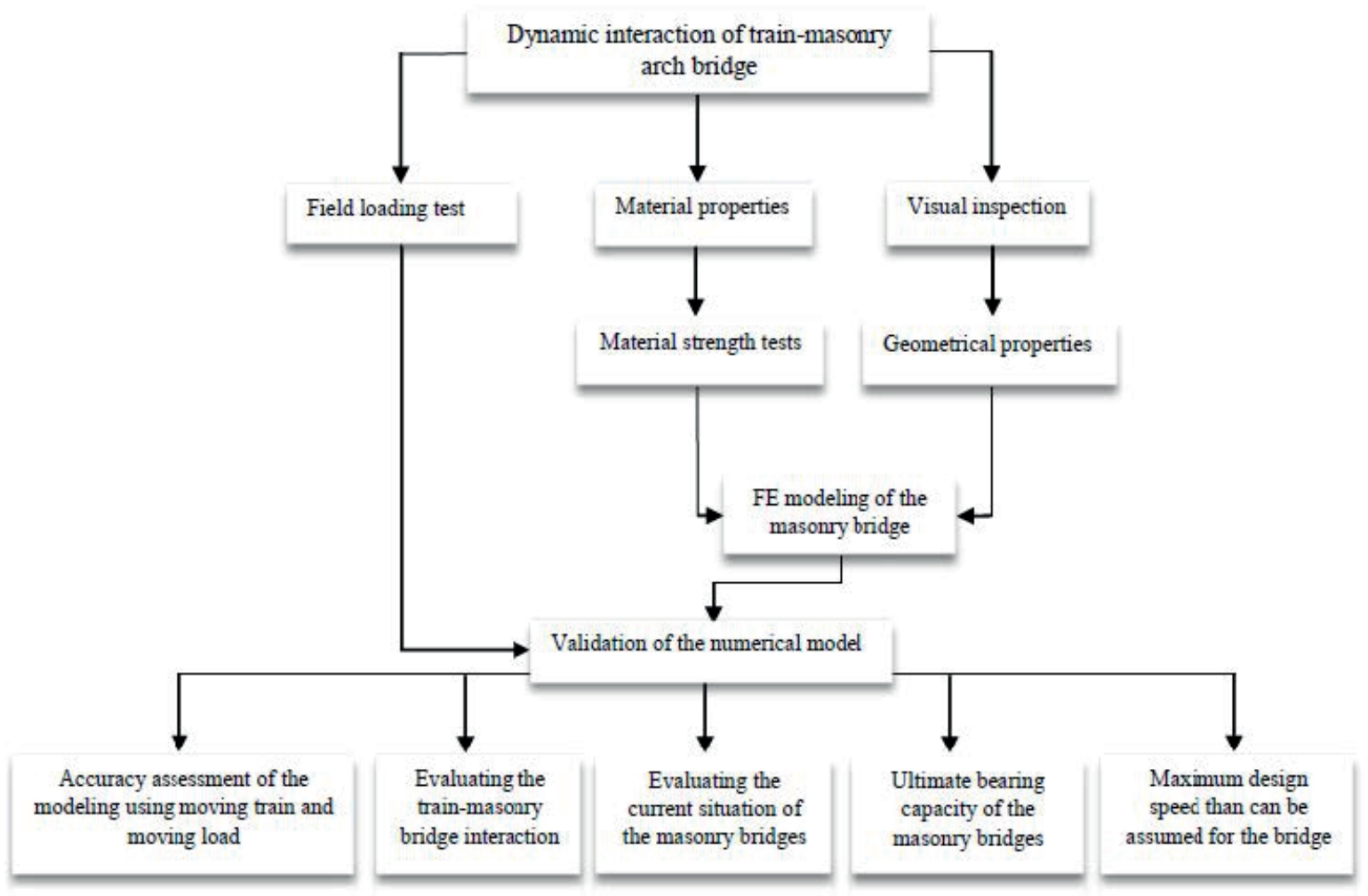

Fig. 1 Research methodology 


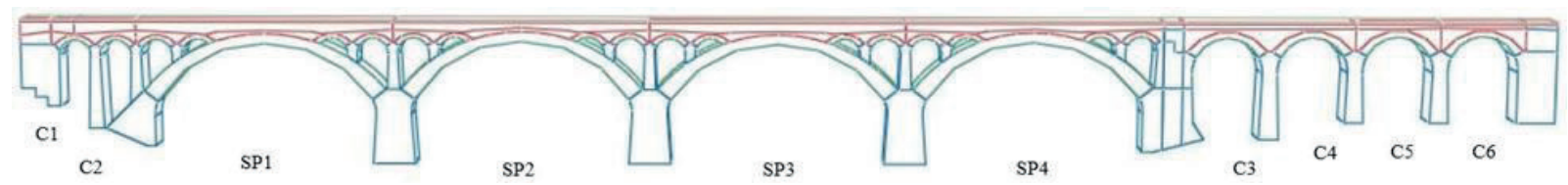

Fig. 3 Spans of the studied bridge

Table 1 Geometrical specifications of the masonry 475 Bridge

\begin{tabular}{|c|c|c|c|c|c|c|c|}
\hline Span no. & Span length $(\mathrm{m})$ & Arch key thickness (m) & Seat width (m) & Deck width (m) & Pier height (m) & Span height (m) & Pier thickness (m) \\
\hline $\mathrm{C} 1$ & 3.5 & 0.50 & 0.78 & 4.00 & 5.7 & 1.8 & 4.35 \\
\hline $\mathrm{C} 2$ & 3.5 & 0.50 & 0.78 & 4.00 & 8.2 & 1.8 & 1.72 \\
\hline SP1 & 25 & 1.10 & 1.9 & 4.00 & 3.3 & 8 & 5.6 \\
\hline SP2 & 25 & 1.10 & 1.9 & 4.00 & 5.6 & 8 & 4.76 \\
\hline SP3 & 25 & 1.10 & 1.9 & 4.00 & 5.6 & 8 & 4.76 \\
\hline SP4 & 25 & 1.10 & 1.9 & 4.00 & 5.6 & 8 & 4.76 \\
\hline $\mathrm{C} 3$ & 8 & 0.75 & 1.2 & 4.40 & 8.2 & 4 & 2.47 \\
\hline $\mathrm{C} 4$ & 8 & 0.75 & 1.2 & 4.40 & 7.6 & 4 & 2.26 \\
\hline $\mathrm{C} 5$ & 8 & 0.75 & 1.2 & 4.40 & 5.7 & 4 & 2.1 \\
\hline \multirow[t]{2}{*}{ C6 } & 8 & 0.75 & 1.2 & 4.40 & 5.8 & 4 & 2.1 \\
\hline & & & & & 5.8 & & 4.4 \\
\hline
\end{tabular}
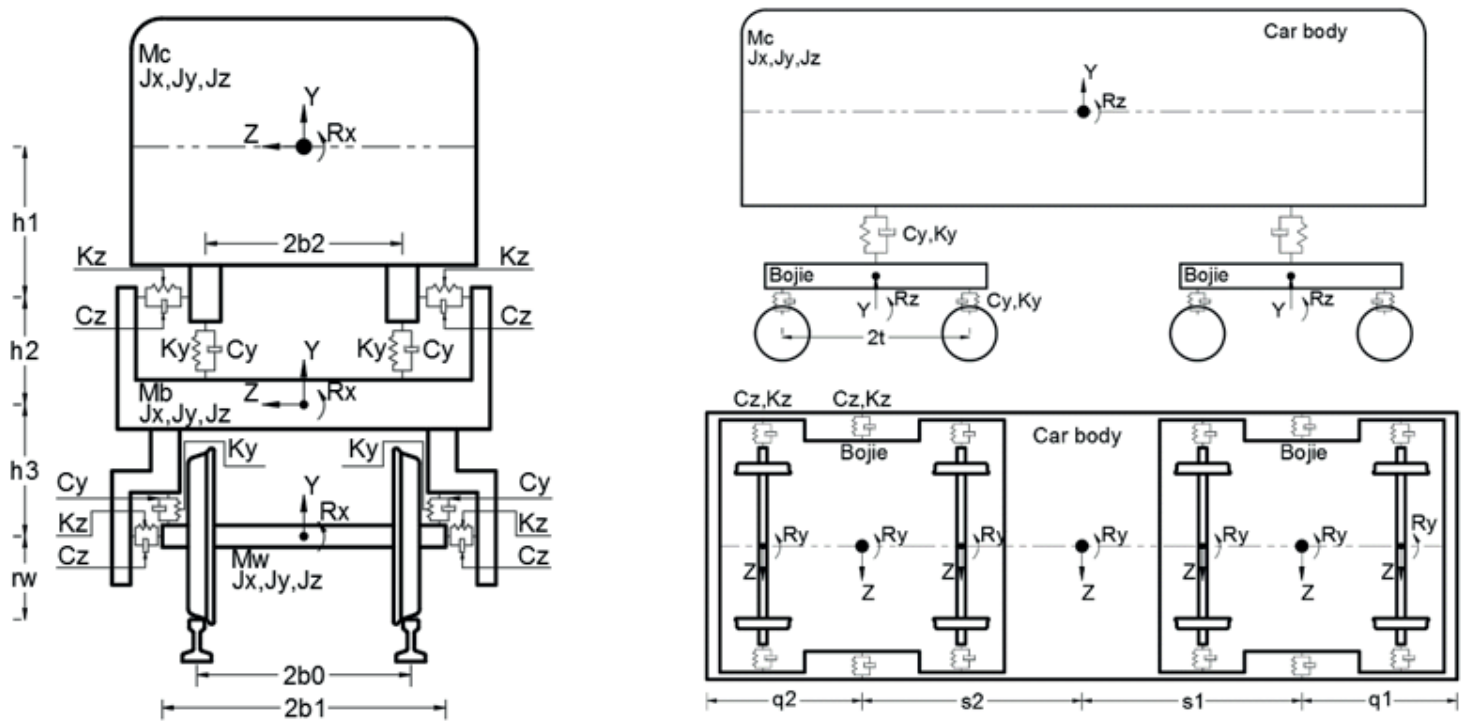

Fig. 4 Mechanical and geometrical specifications of the GT26 train

\section{Train characteristics}

The train used in this study is composed of a 6-axis Gt26 locomotive and a 4-axis wagon passing over the bridge with axial loads of 19 and 20 ton, respectively. The geometrical and mechanical specifications of the train are presented in Fig. 4 and Table 2, respectively.

\section{Finite element modeling}

To control and investigate the research objectives, the 3D FE modeling was done using ABAQUS software [18]. Through the modal analyses in the mesh intervals of 100 to $20 \mathrm{~cm}$, we observed frequency differences less than $0.15 \%$ between 20 and $30 \mathrm{~cm}$ meshes. Thus, \#30 was selected as the dominant mesh size in our analyses (Fig. 5).

To develop the model, a total of 144,038 cubic six-side elements with an average element size of $30 \mathrm{~cm}$ were used. All geometrical and structural features of the bridge, such as expansion joints and fillings, were considered. Also, the piers were considered as constant joints.

Based on the results of material strength test on 9 stone core extracted from different parts of the bridge, the average compressive strength was determined to be $46 \mathrm{MPa}$ for the stone materials. Stone strength classification according to UIC778-3 [1] standard is as follows (Eq. (1)) 
$f_{b}=K f_{m}=0.365 \times 46=16.79 M P a ，$

where $f_{b}$ is a stone strength property, $K$ is the reduction index, which is obtained through the tests, and $f_{m}$ is average compressive stone strength. Since $K$ is estimated to be 0.365 for the 9 extracted samples [1], the stone strength $\left(f_{b}\right)$ was determined to be $16.79 \mathrm{MPa}$.

To set material properties of the model, the initial modulus of elasticity was extracted according to the equations proposed by UIC778-3 [1]. So, for stone materials and cement mortar, we have Eq. (2):
$E=5000+300 f_{b}$,

where $E$ is the equivalent modulus of elasticity. Based on the determined stone strength, $E$ was estimated as $10.04 \mathrm{GPa}$.

To calibrate the FE model (Fig. 6), it was tried to minimize the difference between the measured modal parameter of the bridge and the one calculated with FEM through manipulating the parameters such as mechanical properties of the materials. Then, in order to verify the updated model, the vertical displacement values at the bridge mid-span from the field test and finite element model are compared.

Table 2 Mechanical and geometrical specifications of the GT26 train

\begin{tabular}{|c|c|c|c|c|}
\hline Description & Name & Unit & Power car & Passenger cars \\
\hline Body dimensions & s1; s2; q1; q2; h1 & $\mathrm{m}$ & $6.25 ; 6.25 ; 4.3 ; 4.3 ; 0.7$ & $4.93 ; 4.93 ; 2.6 ; 2.6 ; 0.7$ \\
\hline Body mass & $\mathrm{Mc}$ & ton & 68 & 59 \\
\hline Inertia moment & $\mathrm{Jx} ; \mathrm{Jy} ; \mathrm{Jz}$ & ton. $\mathrm{m}^{2}$ & $180 ; 3500 ; 3500$ & $85 ; 2900 ; 2870$ \\
\hline Bogie mass & $\mathrm{Mb}$ & ton & 3.4 & 3 \\
\hline Bogie inertia moment & $\mathrm{Jx} ; \mathrm{Jy} ; \mathrm{Jz}$ & ton. $\mathrm{m}^{2}$ & $1.76 ; 2.5 ; 5$ & $1.55 ; 2.4 ; 4.6$ \\
\hline Stiffness of the secondary suspension system & $\mathrm{Kz} ; \mathrm{Ky}$ & $\mathrm{KN} / \mathrm{m}$ & $220 ; 1040$ & $105 ; 810$ \\
\hline Damping of the secondary suspension system & $\mathrm{Cz} ; \mathrm{Cy}$ & $\mathrm{KNS} / \mathrm{m}$ & $95 ; 120$ & $40 ; 45$ \\
\hline Dimensions of the secondary suspension system & $\mathrm{b} 2 ; \mathrm{h} 2$ & $\mathrm{~m}$ & $0.95 ; 0.4$ & $0.8 ; 0.4$ \\
\hline Stiffness of the primary suspension system & $\mathrm{Kz}$; Ky & $\mathrm{KN} / \mathrm{m}$ & $2890 ; 1683$ & $2350 ; 970$ \\
\hline Damping of the primary suspension system & $\mathrm{Cz} ; \mathrm{Cy}$ & $\mathrm{KNS} / \mathrm{m}$ & $80 ; 35$ & $62 ; 25$ \\
\hline Mass of axle-wheel & $\mathrm{Mw}$ & ton & 1.8 & 1.8 \\
\hline Inertial moment of axle-wheel & $\mathrm{Jx} ; \mathrm{Jy} ; \mathrm{Jz}$ & ton. $\mathrm{m}^{2}$ & $2.1 ; 2.1 ; 0.043$ & $2.1 ; 2.1 ; 0.043$ \\
\hline Primary suspension system and wheel & b0; b1; h3; t; rw & $\mathrm{m}$ & $0.75 ; 0.9 ; 1 ; 1.7 \& 1 ; 0.5$ & $0.75 ; 0.9 ; 1 ; 1.7 ; 0.5$ \\
\hline
\end{tabular}
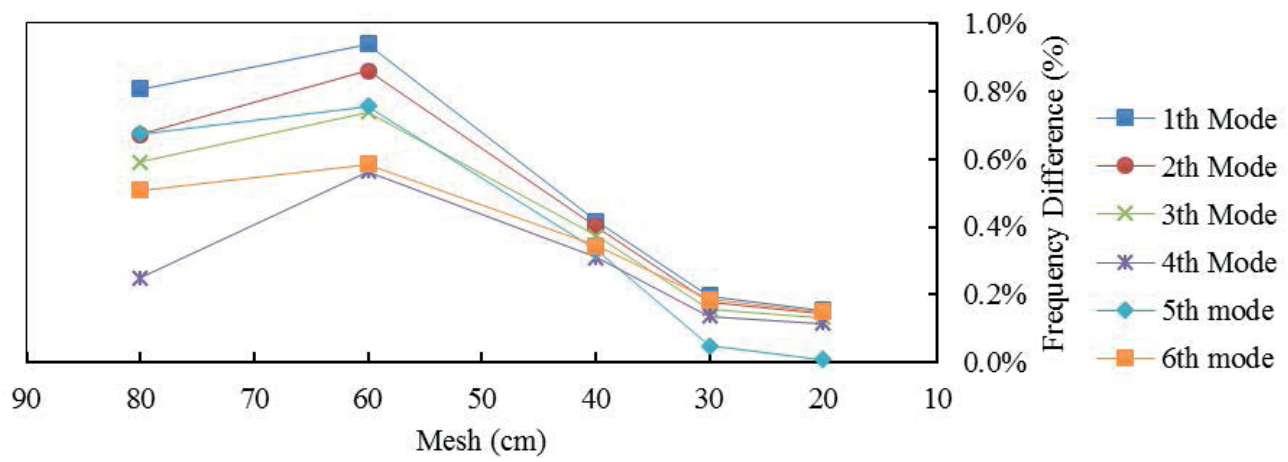

Fig. 5 The convergence of the first six modes based on mesh dimensions

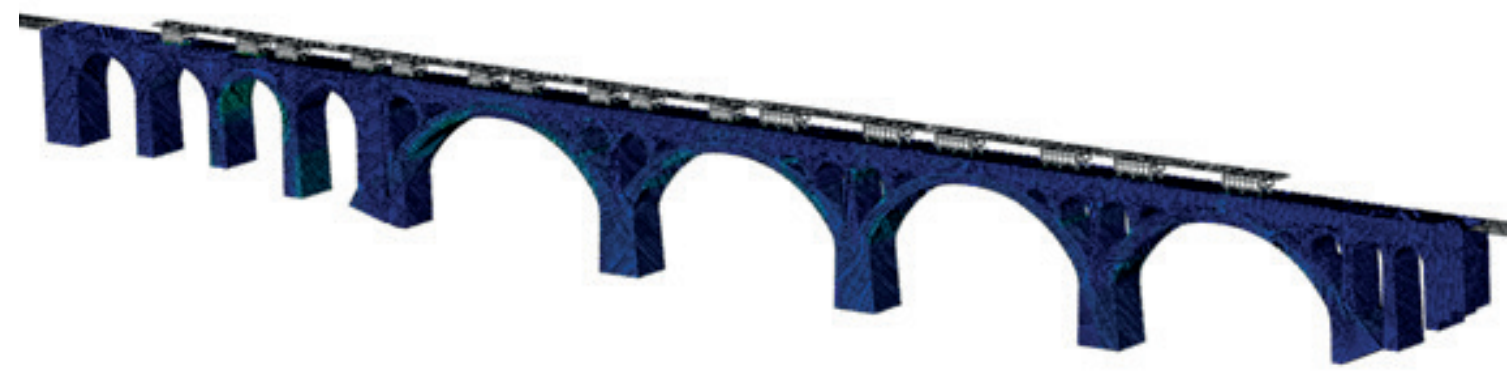

Fig. 6 The 3D FE model developed in ABAQUS environment for 475 Bridge and GT26 Train 
In all spans, $E$ was used as the calibration parameter for minimizing the difference of deformation responses and natural frequencies between the FEM and field test results. Moreover, as shown in Table 3, by estimating $E$ for each span, it is possible to estimate compressive strength using the equation proposed by Euro-code [19] Standard (Eq. (3)).

$$
f_{K}=\frac{E}{K_{E}}
$$

Table 4, Figs. 7 and 8 present natural frequency and modal shapes of the bridge computed through the updated masonry Young's modulus and calibrated numerical model. It is worth mentioning that the free resonances of the accelerometers (Table 4) were used for this purpose.

Considering the importance of initial modes and accumulation of $>90 \%$ of the modal mass in modes 1 and 2 , UIC778-3 [1] have issued a code by which the frequency differences between modes 1 and 2 obtained through the

Table 3 Initial and calibrated elasticity modulus and compressive strength of the modeled material (is set to 1000)

\begin{tabular}{lcccc}
\hline \multirow{2}{*}{ Span No. } & \multicolumn{2}{c}{$\begin{array}{c}\text { Elasticity Modules } \\
(\mathrm{GPa})\end{array}$} & \multicolumn{2}{c}{$\begin{array}{c}\text { Compressive Strength } \\
(\mathrm{MPa})\end{array}$} \\
\hline \multirow{2}{*}{ 1st } & Initial & Calibrated & Initial & Calibrated \\
2nd & 10.04 & 7.82 & 10.04 & 7.82 \\
3rd & 10.04 & 7.34 & 10.04 & 7.34 \\
4th & 10.04 & 7.24 & 10.04 & 7.24 \\
Other spans & 10.04 & 7.75 & 10.04 & 7.75 \\
\hline
\end{tabular}

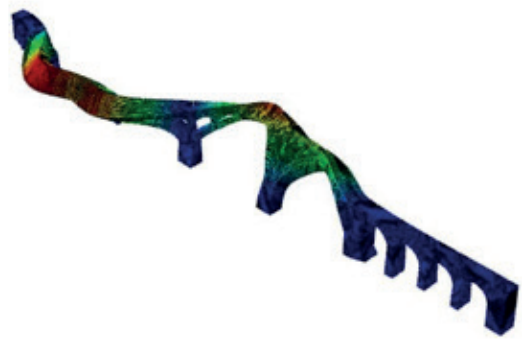

$2^{\text {nd }}$ mode

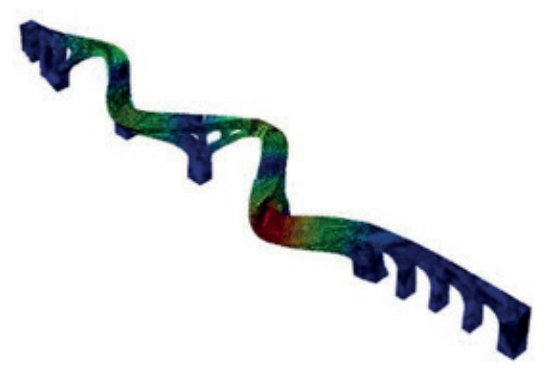

$4^{\text {th }}$ mode

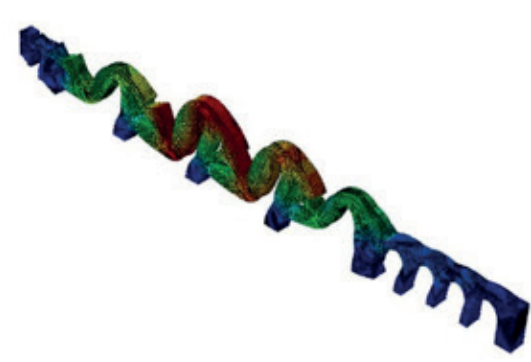

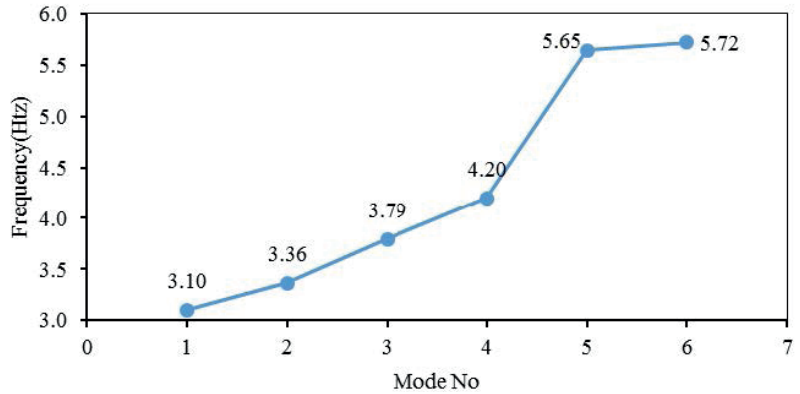

Fig. 8 Modal frequency

field test and FE model can be $15 \%$ and $25 \%$, respectively. Based on Table 4, the natural frequency difference obtained from field test and FE model in shape modes 1 and 2 is less than $13.5 \%$.

All elements existing in nature are deformable. Indeed, there is not absolute solid material in the universe. However, with respect to the deformability level, some substances can be considered as solid relative to others. In the present study, train modeling was done using the discrete rigid elements and some springs and dampers in the horizontal and vertical directions were considered as the connection

Table 4 Comparison of natural frequencies obtained through field test [10] and the FE

\begin{tabular}{lcccc}
\hline $\begin{array}{l}\text { Mode } \\
\text { No. }\end{array}$ & $\begin{array}{c}\text { Dynamic } \\
\text { Test }\end{array}$ & $\begin{array}{c}\text { Finite } \\
\text { Element }\end{array}$ & $\begin{array}{c}\text { Allowable Variance } \\
\text { (According to UIC) }\end{array}$ & Variance \\
\hline 1 & 2.73 & 3.10 & $\% 15$ & $\% 13.5$ \\
2 & 3.51 & 3.36 & $\% 25$ & $\% 4.27$ \\
3 & 3.97 & 3.79 & - & $\% 4.53$ \\
\hline
\end{tabular}

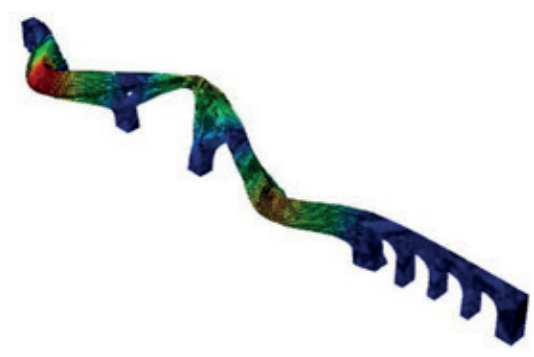

$3^{\text {rd }}$ mode

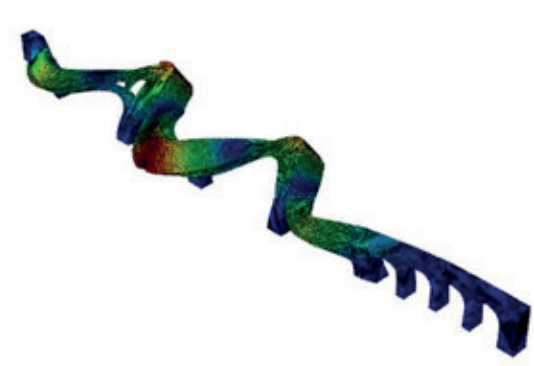

$6^{\text {th }}$ mode

Fig. 7 Modal shapes of the 475 Bridge 
elements of the trains (Figs. 9 and 10). Moreover, based on the Hertz Theory, Hertzian springs were used to simulate the wheels (Fig. 10). To estimate the equivalent stiffness of the Hertzian spring, the relations proposed by Bhaskar et al. [20] were used, where $k_{h}$ is the equivalent stiffness of Hertzian spring, $G$ is shear modulus, $P_{0}$ is contact force, $\vartheta$ is Poisson's ratio, and $R_{e}$ is equivalent wheel radius (Eq. (4)).

$k_{h}=\left[\frac{6 G^{2} P_{0} R_{e}}{(1-\vartheta)^{2}}\right]^{\frac{1}{3}}$

Fig. 11 illustrates the displacement results in the middle of SP4 subjected to the pass of two GT26 locomotives extracted using both field test and FEM analysis, which suggest the desired accuracy of the FE modeling.

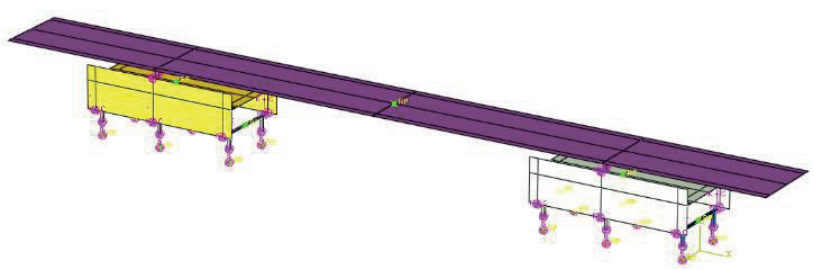

Fig. 9 The 3D FEM of train GT26

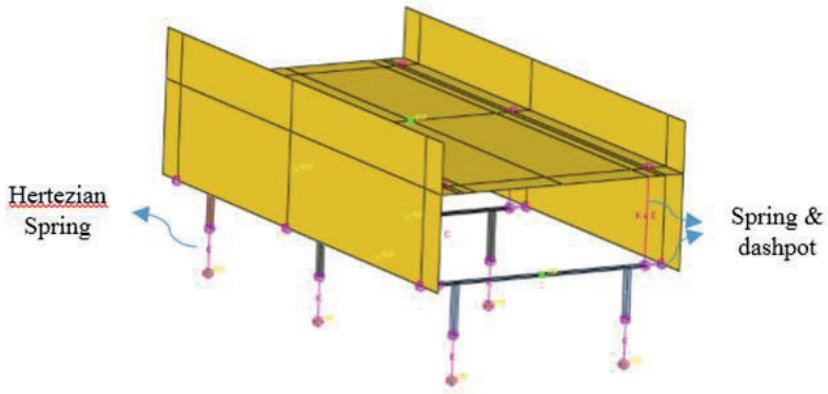

Fig. 10 The suspension systems and Hertzian springs

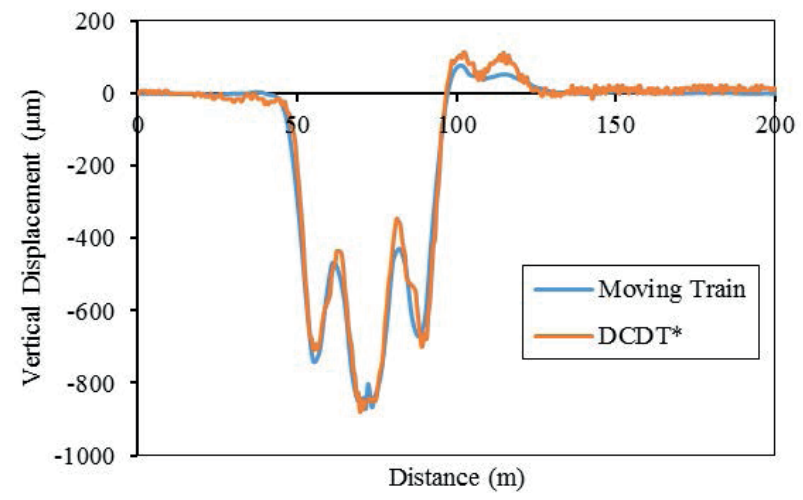

*DCDT: field test result exerted from Deflected Cantilever isplacement Transducer

Fig. 11 The comparison of FEM and field test results for displacement occurred in the middle part of SP4 for the case with two locomotives traveling
Reducing the simplifications and a precise correspondence of the model with reality enhance the accuracy of the analyses. The majority of the previous studies in this regard focus on a moving load on masonry bridges. In comparison, a moving train was considered instead of a moving load to increase the accuracy of the modeling results. The results show that the modeling results for the case of moving load are $10 \%$ greater than the case of moving the train (Fig. 12).

\section{Evaluation of the bridge-train interaction}

Investigating the interaction of bridge-train system using FE modeling provides valuable time history responses, which allow studying the behavior of the structure during the analyses. Figs. 13(a)-(c) present time-history results for displacement, stress, and acceleration for two locomotives passing at a speed of $36 \mathrm{Km} / \mathrm{h}$ in the middle of SP4. Based on the displacement curve, it is seen that displacement initially occurs by entering the first Bogie. Then, after approaching Bogies 2 and 3, the displacement level increases. Next, with a slight resonance in second 9, the effects of Bogies 2 and 3 are separated. Finally, after exiting Bogie 4 from the arch, the lateral piers show their effects.

In dynamic problems, analyses are done with an incremental approach. In this situation, the applied loads and train speeds increase proportionally to the increments. It has to be noted that at the beginning of the analyses the applied loads and train speeds are zero while along with the analysis they linearly grow up to the assigned values. To analyze the conditions of the bridge, a train with 1 locomotive and 3 wagons was used. Fig. 14 presents the train speed effects in the SP4 under axle load of 20 ton and Fig. 15 presents the axle load effects under train speed of $60 \mathrm{~km} / \mathrm{h}$ respectively.

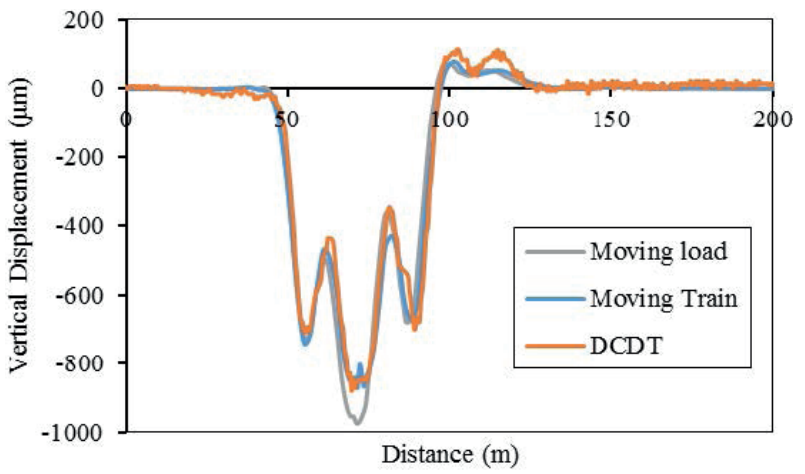

Fig. 12 The comparison of the moving train, moving load, and field test results for displacement occurred in the middle part of SP4 for the case with two locomotives traveling 

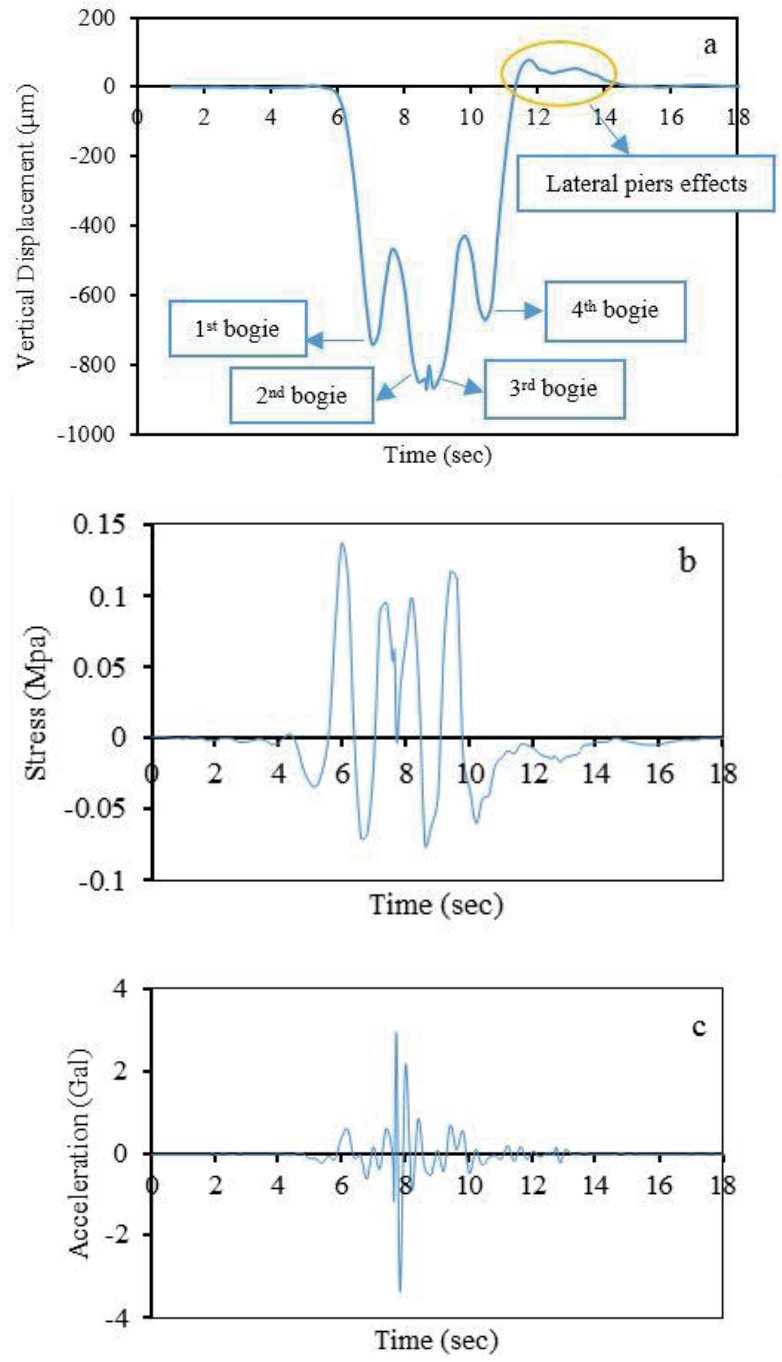

Fig. 13 Results in the middle part of SP4 for the case with two locomotives traveling: (a) displacement, (b) stress and (c) acceleration

\section{Limit state assessment of serviceability stresses}

The bridge was analyzed using the velocities of $0-160$ $\mathrm{km} / \mathrm{h}$ and axial loads of 20,25, and 30 ton. An increase in the axial load and passing speed resulted in an increase in the bridge responses. However, as can be seen in Fig. 16, the peak acceleration responses occur at a velocity of 120 $\mathrm{Km} / \mathrm{h}$, which is due to the closeness of loading frequency and bridge natural frequency (Eq. (5)). This phenomenon suggests that the dynamic impact coefficients proposed in the regulations are not necessarily able to accurately predict the dynamic forces in all loading speeds.

$f=\frac{V}{S}$,

where $f$ is frequency, $V$ is velocity and $S$ is the distance between loading points.

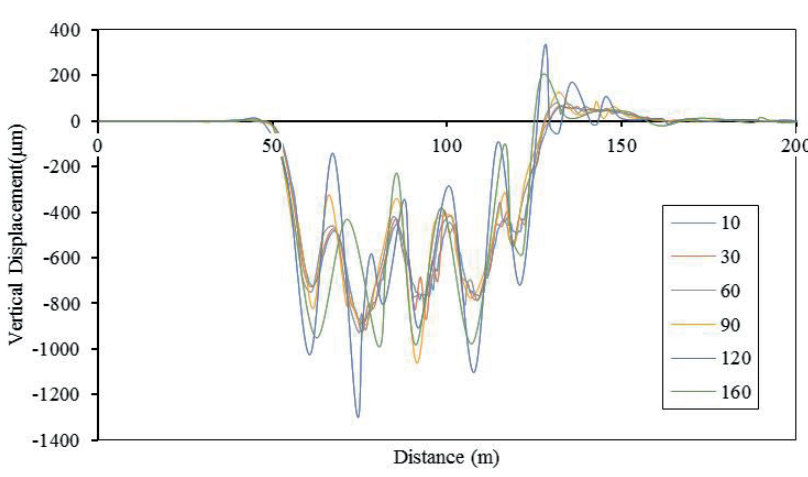

Fig. 14 Train speed effects in the middle part of SP4 under axle load of 20 ton

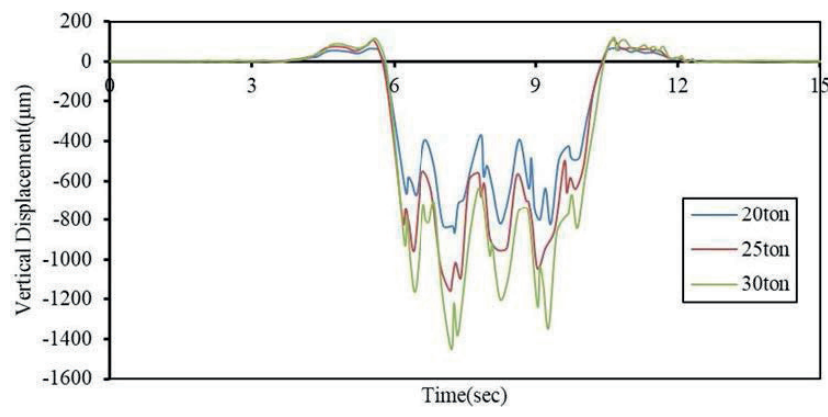

Fig. 15 Axle load effects in the middle part of SP4 under train speed of $60 \mathrm{~km} / \mathrm{hr}$

According to BD-91/04 [21], the allowable compressive stress under the serviceability limit state with the loading pattern of $D+1.2 L$ does not exceed $0.4 f_{k}$. Considering the 7.82 MPa compressive strength of the studied stones of SP1, the allowable compressive strength was calculated to be $3.13 \mathrm{MPa}$. Fig. 17 shows compressive stress results for SP1. The results suggest the adequacy of this parameter for all speeds and axial loads. Also, Table 5 shows compressive stress results for all arches under a passing speed of $60 \mathrm{~km} / \mathrm{h}$ and an axle load of $20 \mathrm{ton}$.

Standard BD-91/04 [21] limits the allowable eccentricity of the compressive arch to, where $h$ is the arch thickness. The stone blocks in the arch are mainly under compression and show considerable strength. However, an increase in the axial loads caused by the pavement enhances eccentricity $(e=M / P)$, leading to tensile stresses in the lower fiber and, consequently, separation and failure of stone blocks in the arch. As mentioned earlier, BD-91/04 [21] recommends the allowable eccentricity as $e<0.25 h$. Figs. 18 (SP1)-(C4) present eccentricity values for 25-m and 8-m main spans in different speeds and axle loads. As an instance, Table 5 presents the current situation of the bridge under the passing speed of $60 \mathrm{~km} / \mathrm{h}$ and axle load of 20 ton. 

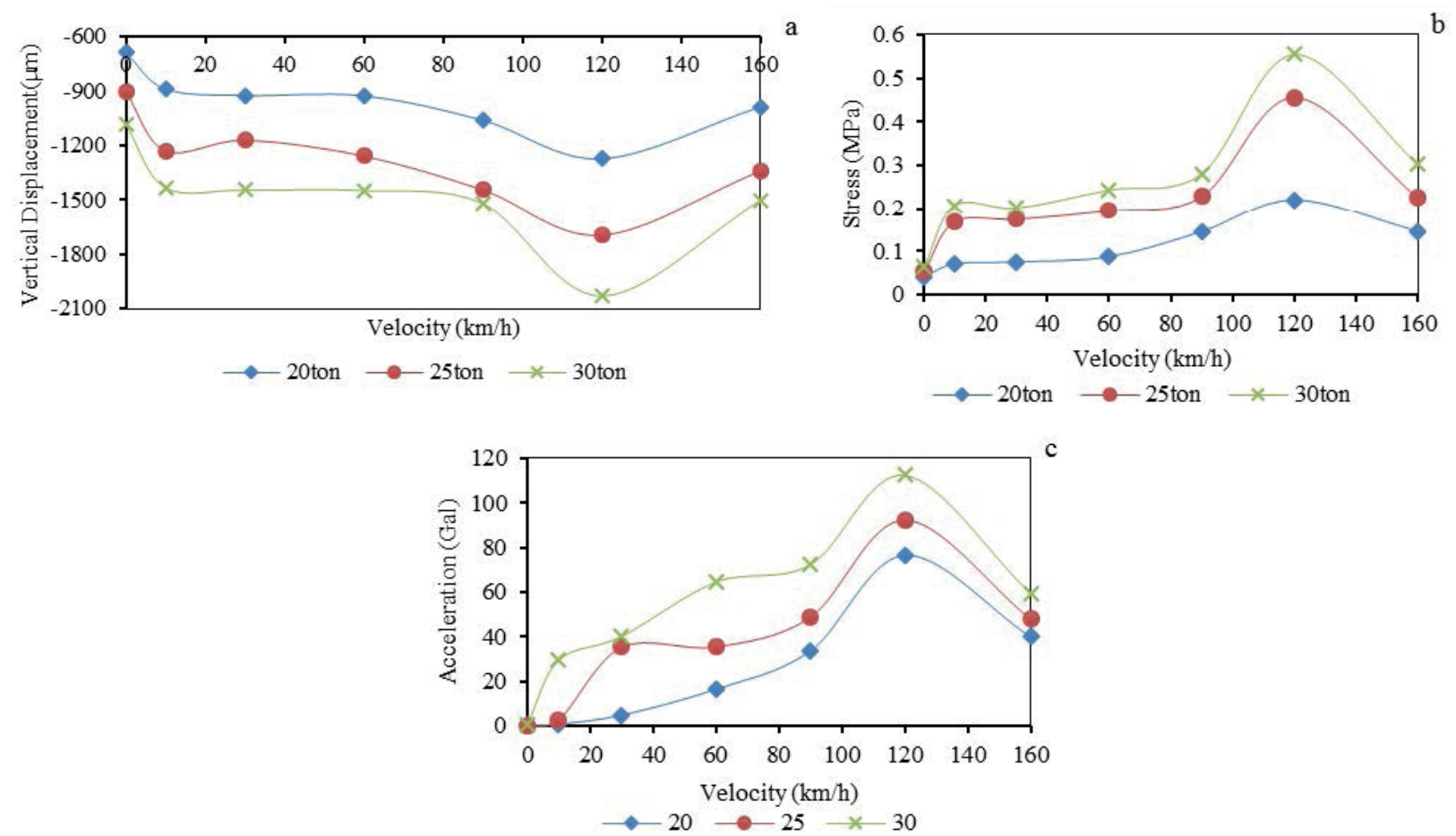

Fig. 16 The maximum results of SP3 mid-span: (a) displacement, (b) stress, and (c) acceleration

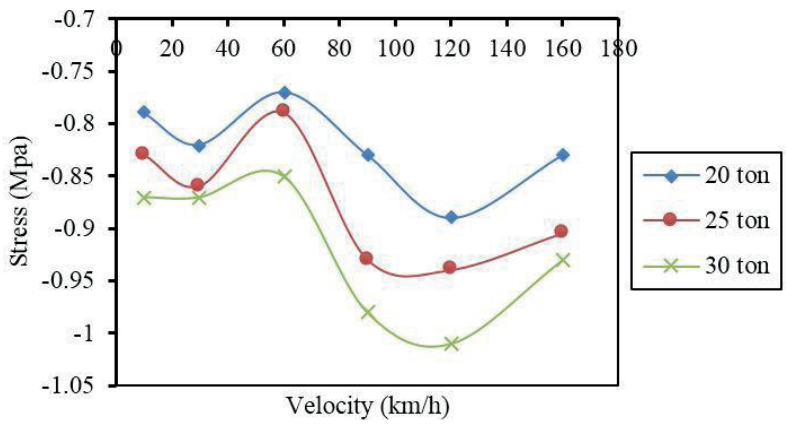

Fig. 17 The maximum results of compressive stress (SP1 mid-span)

Results show that all applied compressive stresses are in the allowable range but with an increase in the axial load and travel speed, the eccentricity becomes a problematic issue in the arch spans, which is more severe in $8-\mathrm{m}$ spans compared to the $25-\mathrm{m}$ spans.

\section{Ultimate load carrying capacity}

Ultimate load carrying capacity is defined as the ratio of collapse load to present live load. According to the second revision of UIC 778-3 [1], the 4-hinges mechanism is the most probable damage mode in a single-span arch. Moreover, BD-91/04 [21] has proposed an equation for the analysis of the ultimate load carrying capacity of the masonry bridges (Eq. (6)).

$$
P \leq 0.4 b f_{k}(h-2 e),
$$

where $P$ is the compressive load in the arch section under the ultimate design load and $b$ is the arch section width.

The ultimate bearing capacity of the bridge was determined using both standards. Due to the exceeded geometrical properties of $8-\mathrm{m}$ and $25-\mathrm{m}$ arches from the allowable values in the MEXE method, it cannot be implemented in the 475 Bridge; because MEXE does not provide satisfactory results for span lengths larger than $20 \mathrm{~m}$. In the present study, a 2D model - developed based on material test results and in accordance with UIC 778-3 [1] regulation is proposed as the second step of the analyses. The advanced 3D model, which was calibrated and validated based on field test results in the previous section (FE modeling), is considered as the third step of the analyses. Moreover, a 2D model presented for ultimate load bearing capacity of masonry bridges was developed in Ring software.

The safety factor according to UIC 778-3 [1] for permanent and live loads and materials properties are 1.35, 1.45, and 2.25, respectively. In comparison, BD-91/04 [21] recommends safety factors of 1.65 and 1.35 for the live and permanent loads, respectively.

The 2D model presented in Fig. 19 was developed in ABAQUS based on material test results. As can be seen, details such as joints and ballast were simplified in the model. To develop this model, 4-node elements were used. Moreover, a 3D FE model was calibrated and developed based on field test results. The model incorporates all 
Table 5 Investigating the current situation of the bridge based on the common passing loads (1Dis+3loco) according to BD-91/04[[21]

\begin{tabular}{|c|c|c|c|c|c|c|c|c|}
\hline \multirow{2}{*}{ Span } & \multirow{2}{*}{\multicolumn{2}{|c|}{ Location }} & \multicolumn{2}{|c|}{$S(\mathrm{MPa})$} & \multirow{2}{*}{$h(\mathrm{~mm})$} & \multirow{2}{*}{$e(\mathrm{~mm})$} & \multirow{2}{*}{$e / h$} & \multirow{2}{*}{ BD91/04 } \\
\hline & & & Exerted & Allowable $\left(0.4 f_{k}\right)$ & & & & \\
\hline \multirow{4}{*}{ SP1 } & \multirow{2}{*}{ Middle-Span } & Upper fiber & -0.84 & -3.13 & 1100 & 220.28 & 0.20 & $\mathrm{OK}$ \\
\hline & & Lower fiber & 0.08 & -3.13 & & & & \\
\hline & \multirow{2}{*}{ Quarter-Span } & Upper fiber & -0.42 & -3.13 & 1350 & 30.38 & 0.02 & $\mathrm{OK}$ \\
\hline & & Lower fiber & -0.56 & -3.13 & & & & \\
\hline \multirow{4}{*}{ SP2 } & \multirow{2}{*}{ Middle-Span } & Upper fiber & -0.84 & -2.94 & 1100 & 211.66 & 0.19 & $\mathrm{OK}$ \\
\hline & & Lower fiber & 0.06 & -2.94 & & & & \\
\hline & \multirow{2}{*}{ Quarter-Span } & Upper fiber & -0.39 & -2.94 & 1350 & 34.91 & 0.03 & $\mathrm{OK}$ \\
\hline & & Lower fiber & -0.53 & -2.94 & & & & \\
\hline \multirow{4}{*}{ SP3 } & \multirow{2}{*}{ Middle-Span } & Upper fiber & -0.71 & -2.90 & 1100 & 184.43 & 0.17 & $\mathrm{OK}$ \\
\hline & & Lower fiber & 0.00 & -2.90 & & & & \\
\hline & \multirow{2}{*}{ Quarter-Span } & Upper fiber & -0.40 & -2.90 & 1350 & 51.78 & 0.04 & $\mathrm{OK}$ \\
\hline & & Lower fiber & -0.64 & -2.90 & & & & \\
\hline \multirow{4}{*}{ SP4 } & \multirow{2}{*}{ Middle-Span } & Upper fiber & -0.87 & -3.10 & 1100 & 206.86 & 0.19 & $\mathrm{OK}$ \\
\hline & & Lower fiber & 0.05 & -3.10 & & & & \\
\hline & \multirow{2}{*}{ Quarter-Span } & Upper fiber & -0.35 & -3.10 & 1350 & 59.20 & 0.04 & $\mathrm{OK}$ \\
\hline & & Lower fiber & -0.60 & -3.10 & & & & \\
\hline \multirow{4}{*}{$\mathrm{C} 4$} & \multirow{2}{*}{ Middle-Span } & Upper fiber & -0.26 & -3.08 & 750 & 937.5 & 1.25 & N.G \\
\hline & & Lower fiber & 0.26 & -3.08 & & & & \\
\hline & \multirow{2}{*}{ Quarter-Span } & Upper fiber & -0.08 & -3.08 & 800 & 17.44 & 0.02 & $\mathrm{OK}$ \\
\hline & & Lower fiber & -0.06 & -3.08 & & & & \\
\hline
\end{tabular}
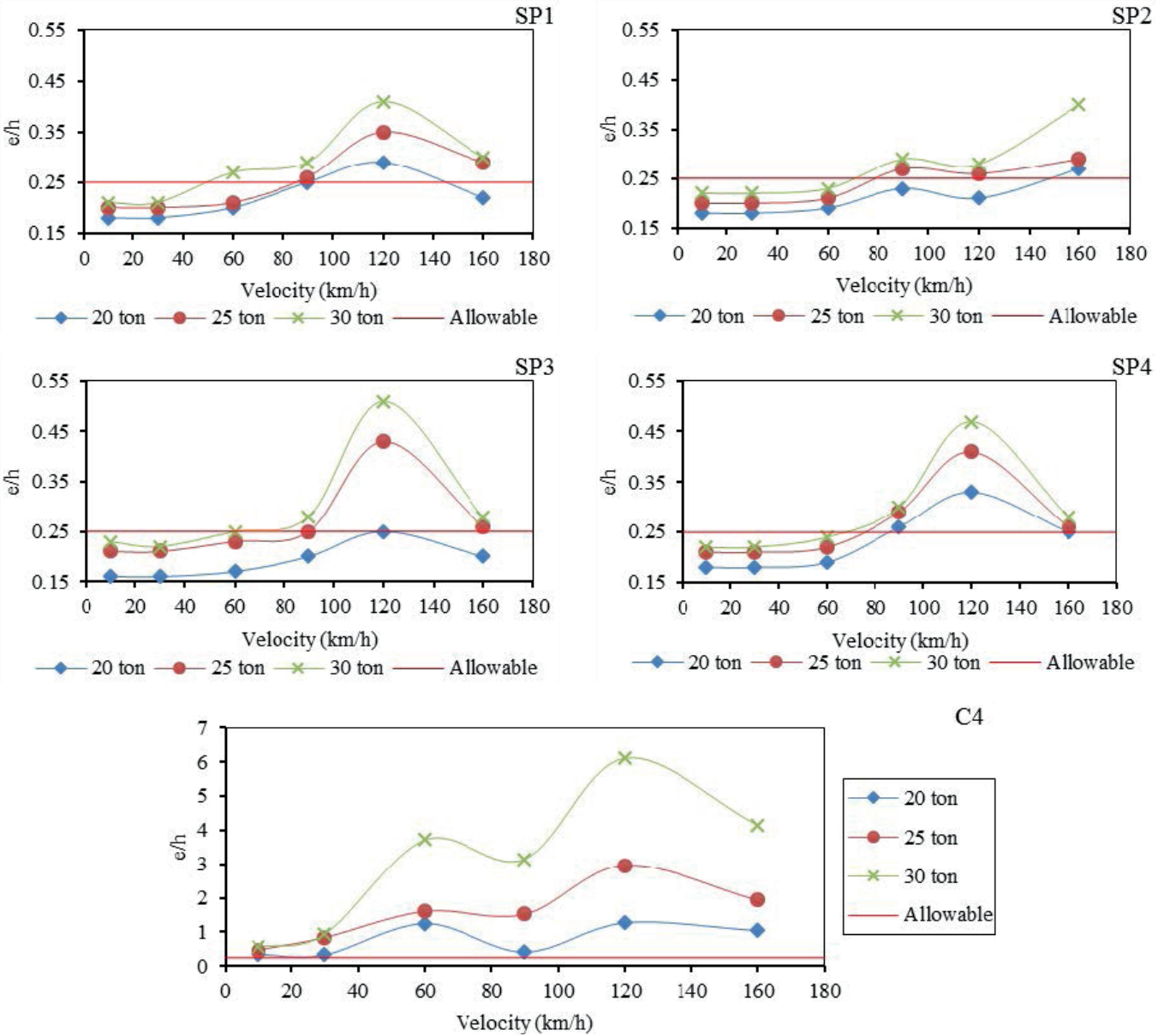

Fig. 18 The effect of axial load and train speed on the eccentricity factor 


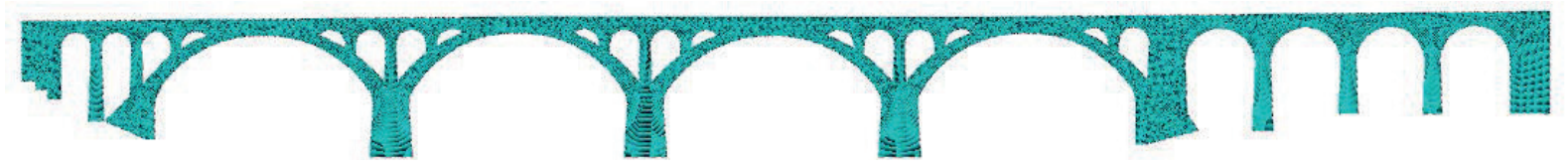

Fig. 19 The simple 2D FM model of the 475 Bridge

structural details of the bridge. Nonlinear modeling of the materials was completely considered in the 3D model such that to nonlinearly investigate displacements in the plastic joints. Fig. 20 presents the stress-strain diagram of the masonry bridges [19].

The Ring software [22] is recommended by UIC 778-3 [1] for extracting the ultimate bearing capacity of the masonry bridge. This software homogenizes solid blocks using the limit state method such that single-ring and multi-ring arches are modeled as the structure in the plan and are composed of solid assembled blocks. Using this software allows determining the collapse load and mechanism.

Clearly, for any new position, the moving vehicle has a specific load coefficient. When the standard LM71 [23] load (Fig. 21) is applied to the middle and the quarter of each arch, collapse load and mechanisms were determined. The collapse mechanism for both $8-\mathrm{m}$ and $25-\mathrm{m}$ spans was determined using the ABAQUS (Figs. 22 and 23) and Ring software (Fig. 24). The adequacy factor of the bridge for the state presented in Figs. 22-24 is shown in Table 6. The table also presents the adequacy factor extracted from the developed 2D and 3D models. Table 7 shows the ultimate bearing capacity results of the bridge in accordance with BD-91/04 [21], where $P$ is the axial force and $P_{n}$ is the axial bearing capacity of the section. In the worst case, the difference between the results of these two standards is less than $17 \%$.

The results show that among all models, the 3D FEM is the most efficient one and provides a high accuracy; thus, the other ones may overestimate or underestimate the results. Table 8 gives the overestimated and underestimated results of the 2D models and BD-91/04 [21], which

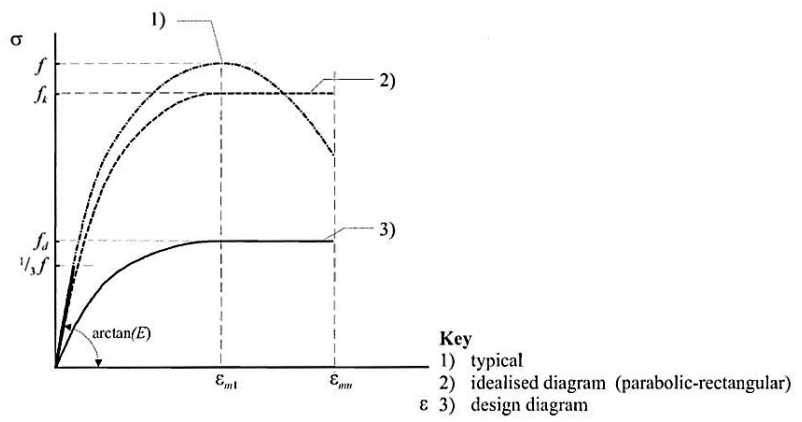

Fig. 20 Stress-strain diagram of the stone materials [[19]

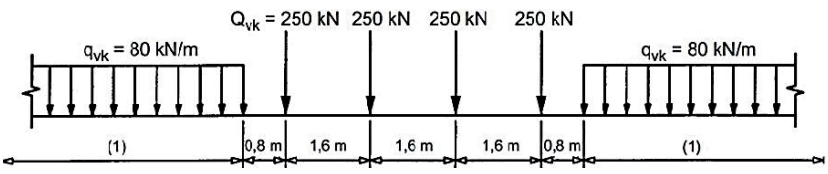

Fig. 21 Standard LM71 loading according to UIC 776-1 [23] standard

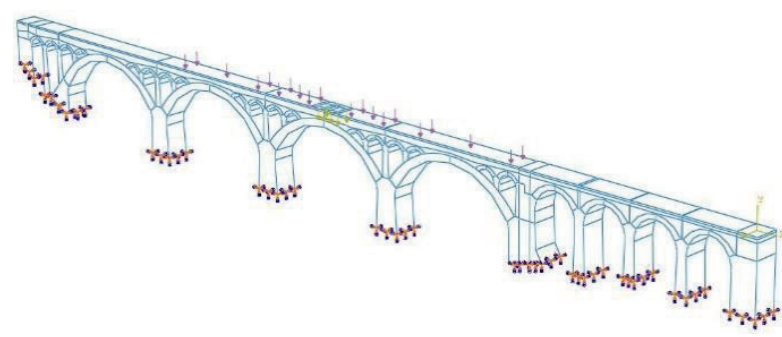

(a)

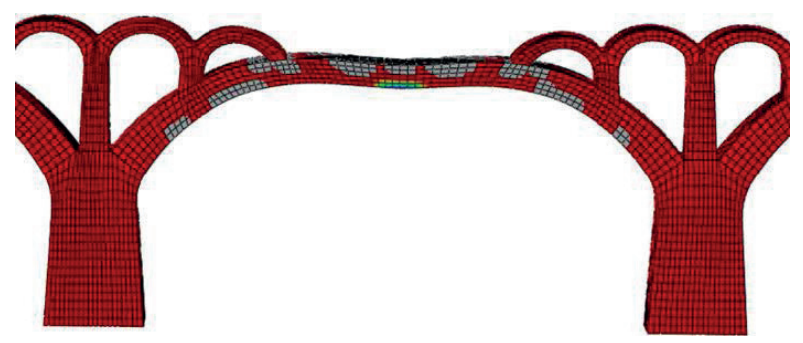

(b)

Fig. 22 3D analyses in the Middle of the 25-m Spans in ABAQUS: a) Loading and b) Results

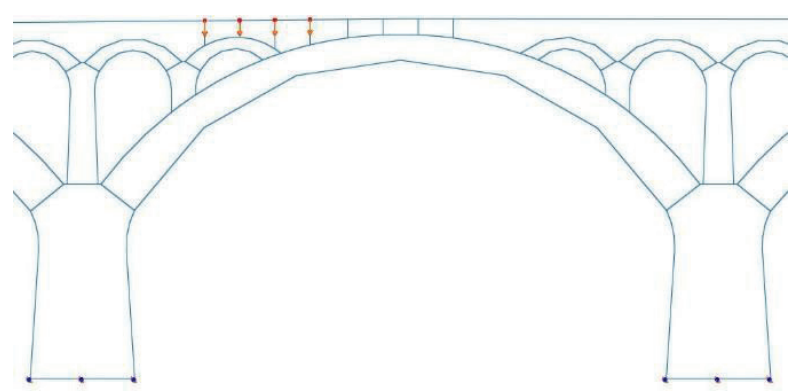

(a)

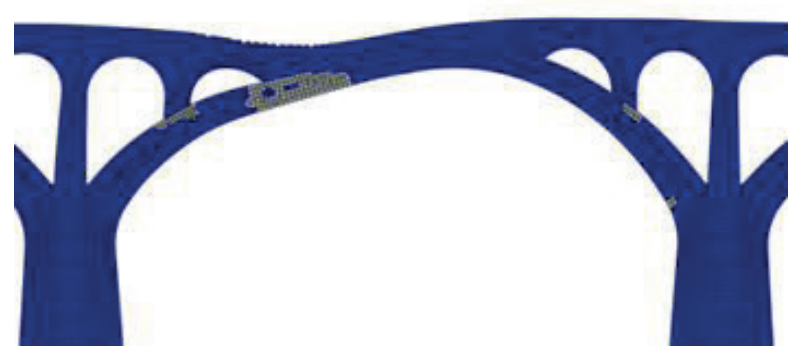

(b)

Fig. 23 2D analyses in the Quarter of the 25-m Spans in ABAQUS: a) Loading and b) Results 


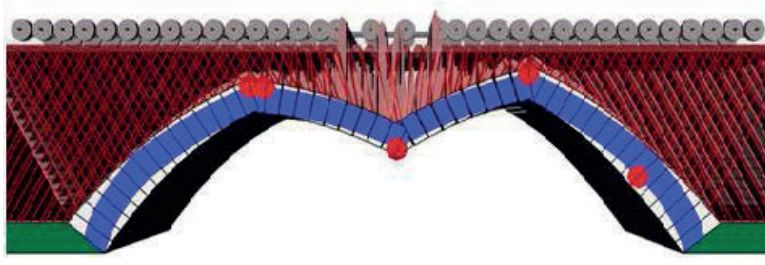

(a)

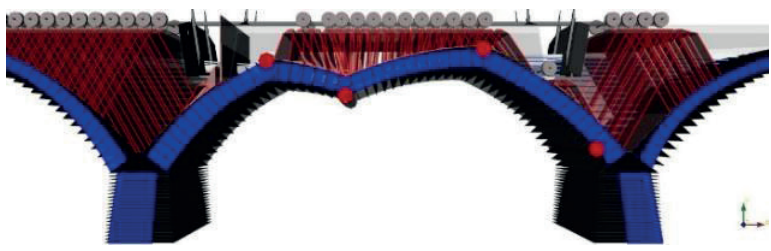

(b)

Fig. 24 2D analyses in the (a) Middle-Span and (b) Quarter-Span of the 25-m and 8-m spans in Ring

Table 6 Ultimate bearing capacity under the standard LM71 loading

\begin{tabular}{lccc}
\hline Span length $(\mathrm{m})$ & Model Type & Quarter-Span & Middle-Span \\
\hline \multirow{3}{*}{25} & 3D (FEM) & 2.48 & 2.60 \\
& 2D (FEM) & 2.78 & 3.03 \\
& 2D (Ring) & 1.99 & 2.92 \\
8 & 3D (FEM) & 4.76 & 5.49 \\
& 2D (FEM) & 5.55 & 6.19 \\
& 2D (Ring) & 5.51 & 5.52 \\
\hline
\end{tabular}

were compared to the $3 \mathrm{D}$ FE model. The results show that the 2D model in the larger span gives larger overestimation and underestimation differences. However, the 2D models can be accurately applied in simple bridges without secondary arches.

\section{Conclusions}

The safety and serviceability of an old masonry arch bridge over 70 years old, which is still under service, was explored in this study. For this purpose, a comprehensive 3DFEM is developed and calibrated using the results of field dynamic load test results [10]. Then, after assessment of the effects of the moving load against the moving
Table 8 Comparison of ultimate bearing capacity between 2D and 3D FE models

\begin{tabular}{lccc}
\hline Span length (m) & Model Type & Quarter-Span & Middle-Span \\
\hline \multirow{3}{*}{25} & 3D (FEM) & 1.00 & 1.00 \\
& 2D (FEM) & 1.12 & 1.16 \\
& 2D (Ring) & 0.80 & 1.12 \\
& BD-91/04 & 1.22 & 1.06 \\
& 3D (FEM) & 1.00 & 1.00 \\
& 2D (FEM) & 1.17 & 1.13 \\
& 2D (Ring) & 1.16 & 1.01 \\
& BD-91/04 & 0.84 & 0.72 \\
\hline
\end{tabular}

train and the effects of train speed and axle load on bridge responses, the current situation of the bridge in terms of serviceability and ultimate state is determined.

Based on the result, it is clear that the results of moving load are not equal with the results of the moving train. For example, the arch mid-span deflection obtained using the moving load show a $10 \%$ overestimation while those of the moving train are consistent with the field test results.

The results showed that the maximum value of vertical deflection, acceleration, and stress occur at train speed of $120 \mathrm{~km} / \mathrm{h}$.

Based on serviceability limit state, the allowed speed of the train is $80 \mathrm{~km} / \mathrm{hr}$ for a 20 tons axle load. If the axle load increases to 25 tons, the allowed speed is $70 \mathrm{~km} / \mathrm{h}$ and if the axle load increases to 30 tons, the allowed speed should be $40 \mathrm{~km} / \mathrm{h}$.

To estimate the ultimate load carrying capacity of the bridge, a 2D model was developed as the second step of the analyses and a 3D model was developed as the third step of the analyses. Moreover, a 2D model was developed in Ring software and then the obtained results were compared to the proposed method of BD-91/04 [21].

Considering the $3 \mathrm{D}$ model as the most accurate model, it is possible to determine the over/under-estimation of the other models relative to the 3D model. For an $8 \mathrm{~m}$ span,

Table 7 Ultimate bearing capacity under the standard LM71 loading and using BD-91/04 code [21]

\begin{tabular}{|c|c|c|c|c|c|c|c|c|}
\hline Span length (m) & Location & $M / P$ & N.m and $\mathrm{N}$ & $h(\mathrm{~mm})$ & $e(\mathrm{~mm})$ & $P($ ton $)$ & $P_{n}$ (ton) & Loading factors \\
\hline \multirow{4}{*}{25} & \multirow{2}{*}{ Middle-Span } & M & 436000 & \multirow{2}{*}{1100} & \multirow{2}{*}{429} & \multirow{2}{*}{101.70} & \multirow{2}{*}{281} & \multirow{2}{*}{2.76} \\
\hline & & $\mathrm{P}$ & 1017000 & & & & & \\
\hline & \multirow{2}{*}{ Quarter-Span } & M & 629000 & \multirow{2}{*}{1350} & \multirow[b]{2}{*}{516} & \multirow{2}{*}{121.80} & \multirow[b]{2}{*}{367} & \multirow[b]{2}{*}{3.02} \\
\hline & & $\mathrm{P}$ & 1218000 & & & & & \\
\hline \multirow{4}{*}{8} & \multirow{2}{*}{ Middle-Span } & M & 116700 & \multirow{2}{*}{750} & \multirow{2}{*}{311} & \multirow{2}{*}{37.5} & \multirow{2}{*}{148} & \multirow{2}{*}{3.94} \\
\hline & & $\mathrm{P}$ & 375000 & & & & & \\
\hline & \multirow{2}{*}{ Quarter-Span } & M & 197600 & \multirow{2}{*}{800} & \multirow{2}{*}{278} & \multirow{2}{*}{71.11} & \multirow{2}{*}{284} & \multirow{2}{*}{3.98} \\
\hline & & $\mathrm{P}$ & 711800 & & & & & \\
\hline
\end{tabular}


FEM and Ring 2D models overestimated the adequacy factor of the bridge by $13 \%$ and $1 \%$ on the arch middle part and $17 \%$ and $16 \%$ on the arch quarter part, respectively. BD-91/04 method, on the other hand, underestimated the adequacy factor of the bridge by $28 \%$. For a $25-\mathrm{m}$ span, FEM 2D model overestimated the adequacy factor by $16 \%$, the $2 \mathrm{D}$ model of Ring underestimated it by $20 \%$, and BD-91/04 method overestimated it by $22 \%$. Since 3D modeling is relatively time-consuming, and taking the fact that

\section{Refernces}

[1] International Union of Railways "UIC Code 778-3, Recommendations for the inspection, assessment and maintenance of masonry arch bridges", Railway Technical Publications, Paris, France, 2011. [online] Available at: https://www.shop-etf.com/en/recommendations-for-the-inspection-assessment-and-maintenanceof-masonry-arch-bridges-9353?ref=1 [Accessed: 15 February 2020]

[2] Fanning, P. J., Boothby, T. E. "Three-dimensional modeling and full-scale testing of stone arch bridges", Computers \& Structures, 79(29-30), pp. 2645-2662, 2001. https://oi.org/10.1016/S0045-7949(01)00109-2

[3] Frýba, L., Pirner, M. "Load tests and modal analysis of bridges", Engineering Structures, 23(1), pp. 102-109, 2001. https://doi.org/10.1016/S0141-0296(00)00026-2

[4] Brencich, A., Sabia, D. "Experimental identification of a multi-span masonry bridge: The Tanaro Bridge", Construction and Building Materials, 22(10), pp. 2087-2099, 2008.

https://doi.org/10.1016/j.conbuildmat.2007.07.031

[5] Ng, K.-H., Fairfield, C. A. "Monte Carlo simulation for arch bridge assessment", Construction and Building Materials, 16(5), pp. 271$280,2002$.

https://doi.org/10.1016/S0950-0618(02)00020-X

[6] Marefat, M.-S., Ghahremani-Gargary, E., Ataei, S. "Load test of a plain concrete arch railway bridge of 20-m span", Construction and Building Materials, 18(9), pp. 661-667, 2004.

https://oi.org/10.1016/j.conbuildmat.2004.04.025

[7] Caglayan, B. O., Ozakgul, K., Tezer, O. "Assessment of a concrete arch bridge using static and dynamic load tests", Structural Engineering and Mechanics, 41(1), pp. 83-94, 2012.

https://doi.org/10.12989/sem.2012.41.1.083

[8] Carr, A. J., Jáuregui, D. V., Riveiro, B., Arias, P., Armesto, J. "Structural evaluation of historic masonry arch bridges based on first hinge formation", Construction and Building Materials, 47, pp. 569-578, 2013.

https://doi.org/10.1016/j.conbuildmat.2013.05.084

[9] Bayraktar, A., Türker, T., Altunişik, A. C. "Experimental frequencies and damping ratios for historical masonry arch bridges", Construction and Building Materials, 75, pp. 234-241, 2015. https://doi.org/10.1016/j.conbuildmat.2014.10.044

[10] Ataei, S., Miri, A., Jahangiri, M. "Assessing safety of a railway stone arch bridge by experimental and numerical analyses", Gradevinar, 69(11), pp. 1017-1029, 2017. https://doi.org/10.14256/JCE.1612.2016 neither of 2D models over/under-estimation of load carrying capacity exceeds $20 \%$, application of 2D models for ultimate load carrying a capacity assessment of masonry arch bridges is advisable.

\section{Acknowledgment}

Iranian Railways and Assistant Prof. Shervan Ataei, who made possible this research on the $475 \mathrm{~km}$ masonry arch bridge, are gratefully acknowledged by the authors.

[11] Reccia, E., Milani, G., Cecchi, A., Tralli, A. "Full 3D homogenization approach to investigate the behavior of masonry arch bridges: The Venice trans-lagoon railway bridge", Construction and Building Materials, 66, pp. 567-586, 2014.

https://doi.org/10.1016/j.conbuildmat.2014.05.096

[12] Ataei, S., Jahangiri Alikamar, M., Kazemiashtiani, V. "Evaluation of axle load increasing on a monumental masonry arch bridge based on field load testing", Construction and Building Materials, 116, pp. 413-421, 2016.

https://doi.org/10.1016/j.conbuildmat.2016.04.126

[13] Ataei, S., Miri, A., Jahangiri, M. "Assessment of load carrying capacity enhancement of an open spandrel masonry arch bridge by dynamic load testing", International Journal of Architectural Heritage, 11(8), pp. 1086-1100, 2017. https://doi.org/10.1080/15583058.2017.1317882

[14] Jahangiri, M., Zakeri, J.-A. "Dynamic analysis of train-bridge system under one-way and two-way high-speed train passing", Structural Engineering and Mechanics, 64(1), pp. 33-44, 2017. https://doi.org/10.12989/sem.2017.64.1.033

[15] Jahangiri, M., Zakeri, J.-A. "Dynamic Analysis of Two-lane Skewed Bridge and High-speed Train System", Periodica Polytechnica Civil Engineering, 63(3), pp. 695-708, 2019. https://doi.org/10.3311/PPci.13135

[16] Oliveira, D. V., Lourenço, P. B., Lemos, C. "Geometric issues and ultimate load capacity of masonry arch bridges from the northwest Iberian Peninsula", Engineering Structures, 32(12), pp. 3955-3965, 2010 .

https://doi.org/10.1016/j.engstruct.2010.09.006

[17] Ataei, S., Tajalli, M., Miri, A. "Assessment of old load carrying capacity and fatigue life expectancy of a manumental Masonry Arch Bridge by field load testing: a case study of veresk", Structural Engineering and Mechanics, 59(4), pp. 703-718, 2016. https://doi.org/10.12989/sem.2016.59.4.703

[18] ABAQUS Inc. "ABAQUS Analysis user's manual (6.14-2)", [online] Available at: www.simulia.com [Accessed: 15 February 2020]

[19] CEN "Eurocode 6, Design of masonry structures - Part 1-1: General rules for reinforced and unreinforced masonry structures", European Commitee for Standardization, Brussels, Belgium, 2005. [online] Available at: https://eurocodes.jrc.ec.europa.eu/showpage. php?id=136 [Accessed: 15 February 2020] 
[20] Bhaskar, A., Johnson, K. L., Wood, G. D., Woodhouse, J. "Wheelrail dynamics with closely conformal contact Part 1: Dynamic modeling and stability analysis", Proceedings of the Institution of Mechanical Engineers, Part F: Journal of Rail and Rapid Transit, 211(1), pp. 11-26, 1997.

https://doi.org/10.1243\%2F0954409971530860

[21] UK Highways Agency "BD-91/04, Design Manual for Roads and Bridges, Unreinforced masonry arch bridges", Highways Agency, Birmingham, UK, 2004. [online] Available at: http://www.standardsforhighways.co.uk/ha/standards/dmrb/vol2/section2.htm [Accessed: 15 February 2020]
[22] Limit State "RING-Masonry Arch Bridge Analysis Software (3.1)", [online] Available at: http://www.limitstate.com/ring [Accessed: 12 February 2020]

[23] International Union of Railways "UIC Code 776-1, Loads to be considered in railway bridge design", Railway Technical Publications, Paris, France, 2006. [online] Available at: https://www.shop-etf.com/ en/loads-to-be-considered-in-railway-bridge-design [Accessed: 12 February 2020] 